\title{
Alterations of Surfactant Pools in Fetal and Newborn Rat Lungs ${ }^{1}$
}

\author{
C. L. SPAIN, R. SILBAJORIS, AND S. L. YOUNG
}

Department of Medicine, Duke University Medical Center, Durham, North Carolina 27710

\begin{abstract}
Preparation by the developing alveolar epithelium for the transition to air breathing and surfactant secretion at birth are critical components of neonatal survival. We combined morphometric analysis and biochemical assays of lung phospholipids to measure the amount and redistribution of lung surfactant during the perinatal period of rats. Within $10 \mathrm{~min}$ of the start of air breathing, there was a small increase in type II cell lamellar body content by morphometric and biochemical estimates. By $24 \mathrm{~h}$, the whole lung and alveolar extracellular pool surfactant lipid had substantially increased. Subfractionation of the alveolar surfactant pool obtained at four times, from birth to $24 \mathrm{~h}$ of life, demonstrated a 20 -fold increase in the ratio of phospholipid in a tubular myelin-rich fraction compared to a unilamellar vesicle-rich fraction. We conclude that packaging of surfactant may be very active immediately postbirth. Our results also indicate a major shift in the physical forms of extracellular surfactant during the first hours of air breathing. (Pediatr Res 21: 5-9, 1987)
\end{abstract}

\section{Abbreviations}

DSPC, disaturated phosphatidylcholine

PL, phospholipid

LDH, lactate dehydrogenase

LB DSPC, lamellar body disaturated phosphatidylcholine

Immediately after birth, the newborn must transition to air breathing and the effects this has on pulmonary surfactant pools is the subject of this report. Since the demands for refreshing the surfactant at the newly formed air-liquid interface might be suddenly increased, we assumed there would be a large secretory event at this time, as suggested to us by the findings of Rooney et al. (1), Jobe and coworkers $(2,3)$, and others (4-6) in their studies of rabbit and lamb newborns. Such a demand might stress or deplete intracellular reserves. In apparent contrast to this view, Fariday et al. (7) found an increase in intracellular surfactant, according to their indirect index, suggesting a net increase in the intracellular surfactant pool after 5 min of air breathing in rats. These workers also found relative stability in the rat of intracellular surfactant $24 \mathrm{~h}$ after birth.

The alveolar epithelium is still immature at birth in the rat; we chose to study this animal model because of the predictability of its gestational age and because of the relatively immature state of the newborn rat lung. We wanted to focus our efforts on

Received June 6, 1986; accepted August 6, 1986.

Correspondence: Stephen L. Young, M.D., Box 3177, Duke University Medical Center, Durham, NC 27710.

Supported by NHLBI Grant HL-32188.

${ }^{1}$ Portions of this work were presented to the annual meeting of the Society of Pediatric Research, Washington, D.C., May 1985. quantifying changes in the intracellular and extracellular pools of surfactant-associated phospholipid in the late fetal and newborn period, using morphometric and biochemical assays.

\section{METHODS}

Animals. Timed pregnant (previously virgin) Sprague-Dawley females (Zivic-Miller, Allison Park, PA) were received 5 to 7 days prior to parturition. During their late stages of pregnancy, they were allowed food and water ad libitum and were kept in 12-h light-dark cycles. The onset of labor was defined as behavior including nest building and agitation along with vaginal bleeding. Birth began shortly after nesting was complete and was allowed to progress uninterrupted until three to six fetuses were delivered. The air-breathing newborns were kept with the unanesthetized mother. The mothers were then anesthetized with $30-50 \mathrm{mg} / \mathrm{kg}$ pentobarbital intraperitoneally; the remaining fetuses were delivered individually through a hysterotomy. These fetuses (birth group) were more lethargic, but made limb motions. They were still connected to the placenta and made no respiratory efforts. The mothers continued spontaneous breathing during the entire procedure.

No more than $10 \mathrm{~min}$ passed before the newborns $(+10 \mathrm{~min}$ group) were also anesthetized with intraperitoneal pentobarbital, the thoracic contents were rapidly removed and lung wet weight was obtained. Two or three unlavaged lungs were pooled for the phospholipid determinations in all fetal animals. Pooled samples from these animals were regarded as a single determination. Since the +10 min group were expected to have developed in the lower poles of the uterus, we obtained lungs from fetuses in the two lowest and the two highest uterine positions of four mothers on gestational day 22 for separate analysis.

In some fetuses, newborns and 24-h-old pups, a tracheostomy was performed and the lungs were lavaged with $0.3 \mathrm{ml}$ volumes of iced $75 \mathrm{mM} \mathrm{NaCl}$ solution, nine separate times. In other experiments leading to the isolation of lavage subfractions, rat lungs were lavaged three times with iced $154 \mathrm{mM} \mathrm{NaCl}$ solution. The lavages from five animals were pooled for each single determination of lavage subfraction phospholipids. The average breathing time for the $+2 \mathrm{~h}$ group ranged from 1 to $3 \mathrm{~h}$. The female adult lungs were lavaged three times, with $10 \mathrm{ml}$ of iced $154 \mathrm{mM} \mathrm{NaCl}$ solution, and this lavage fluid was subfractionated.

Biochemistry. Lungs from all groups were homogenized in a Potter-Elvehjem tube. Lamellar bodies were isolated according to the method of Duck-Chong (8). The lavage samples were spun in increasing centrifugal force fields, according to the expansion of the technique of Thet et al. (9) given by Magoon, et al. (10) for adult rabbits. The lavage fluid was spun at $50 \times g \times 10 \mathrm{~min}$ $\left(4^{\circ} \mathrm{C}\right)$ to collect the initial pellet (P1). Pellet 2 was obtained by centrifuging the supernatant fluid at $500 \times g \times 20$ min. Pellet 3 was obtained by centrifuging the supernatant from P2 at $1000 \times$ $g$ for $20 \mathrm{~min}$. The first three centrifugations were done in a Sorvall RC2-B centrifuge using a SM-24 rotor (DuPont, Wilmington, DE). P4 was collected by spinning the supernatant of 
$\mathrm{P} 3$ at $60,000 \times g$ for $60 \mathrm{~min}$. The supernatant of P4 was spun at $100,000 \times g$ for $16 \mathrm{~h}$ to obtain P5. [P4 and P5 were obtained using a SW 28.1 rotor in an L2-50 ultracentrifuge (Beckman Instruments, Palo Alto, CA).] S5 represents the entire supernatant left on the final pellet. Damage to the lungs by the lavage procedures was evaluated by measuring LDH in the lavage fluid.

Lipids were extracted by the method of Bligh and Dyer (11) or Folch, et al. (12). DSPC was isolated by the technique of Mason et al. (13); phosphorus was measured according to Bartlett (14). Solvents were of reagent grade (Fisher Scientific, Raleigh, NC) and were not redistilled. Standards of chromatographically pure ${ }^{14} \mathrm{C}$-labeled dipalmitoylphosphatidyl choline (New England Nuclear, Boston, MA) were added in trace amounts to estimate recovery from the extracts and alumina columns. Recoveries averaged greater than $90 \%$ and no corrections were made for these losses.

Morphometry. The right lower lobe was removed, covered with $2 \%$ glutaraldehyde in $85 \mathrm{mM}$ Na cacodylate, and diced with a fresh stainless steel razor blade. Tissue blocks were then transferred to fresh fixative for $2 \mathrm{~h}$ and treated overnight with $2 \%$ $\mathrm{OsO}_{4}$ in $85 \mathrm{mM}$ cacodylate, $4^{\circ} \mathrm{C}$. Osmicated tissue was placed in $2 \%$ aqueous uranyl acetate for $90 \mathrm{~min}$ and dehydrated in a cold acetone series before embedment in epoxy resin (Polyscience, Polarbed 812, Hatfield, PA). These procedures are generally as described by Williams (15). Silver-gray sections were prepared and viewed at $\times 2000$ in a JEOL 100 S electron microscope. Micrographs were obtained of all type II cell profiles (cuboidal epithelial cells containing at least 1 lamellar body profile) from 1 or 2 grid spaces from four sites from each animal.

Fixation of pelleted lamellar bodies and lavage subfractions was done by adding $2 \%$ glutaraldehyde, $2 \%$ tannic acid (Mallinckrodt, St. Louis, $\mathrm{MO}$ ) for $1 \mathrm{~h} . \mathrm{CaCl}_{2}$ was omitted and $3 \mathrm{mM}$ EDTA was added to the cacodylate buffer. Osmication, en bloc uranyl acetate staining, and acetone dehydration was done as for the tissue. To ease handling of the friable pellets, they were encapsulated, after removal to a slab of dental wax, by pouring $2 \%$ agar at $30^{\circ} \mathrm{C}$ over the pellet.

Electron micrographs were printed at $\times 15,000$ on 8 - by 10 inch paper and point counting volumetry was done done using a multipurpose test grid (16). A total of over 70,000 points falling on type II cell profiles were counted. Volume densities were calculated by dividing the points falling on each type II cell organelle profile by the total number of points on type II cells.

Statistics. The significance of differences between mean values were calculated using Student's $t$ test. Multiple comparisons to a control were tested with Dunnett's procedure (17). Significance was set at $p<0.05$. All data are reported as mean \pm SEM.

\section{RESULTS}

At the time of birth, a few animals were allowed to breathe for about $10 \mathrm{~min}$, while their littermates were taken for analysis prior to any possible air breathing. Body weights and lung tissue dry to wet weight ratios indicate these were comparable groups (Table 1). No lung lavage was done on these lungs. The results in Table 1 show the sequence of changes in lung weight and lamellar body DSPC content in unlavaged lungs during the first $24 \mathrm{~h}$ of postnatal life. There is a significantly larger total body weight and a significantly lower lung wet weight at $24 \mathrm{~h}$ compared to those values at birth. The rising dry to wet weight ratio reaches adult levels by $2 \mathrm{~h}$ of age and presumably reflects net extracellular fluid absorption from the lung.

A low power electron micrograph of a pelleted lamellar bodyenriched fraction is shown in Figure 1. The amount of DSPC recovered in the lamellar body enriched fraction from the +10 min group was $26 \%$ greater than obtained in the same fraction from animals not allowed to breathe. There was a slight further increase in lamellar body DSPC of unlavaged lungs by $24 \mathrm{~h}$ of age.

There were no detectable differences in the lamellar body DSPC contents from fetuses in the lowest two uterine positions compared to the highest two uterine positions. The ratio of DSPC in lamellar body fractions from these 16 animals was $0.98 \pm 0.08$ top position/bottom position, in fetuses from four pregnant females.

Morphometric measures gave an independent determination of the type II cell lamellar body pool (Table 2). Point counting volumetry showed $38 \%$ greater type II cell lamellar body volume fraction after $10 \mathrm{~min}$ of air breathing, compared to nonbreathing fetal littermates. At $24 \mathrm{~h}$ of age, the morphometric estimate of lamellar body volume density was the same as the $+10 \mathrm{~min}$ value. No other subcellular compartments changed significantly.

The distribution of DSPC among unlavaged whole lung tissue, the lamellar body fraction and the lavage fluid was measured in

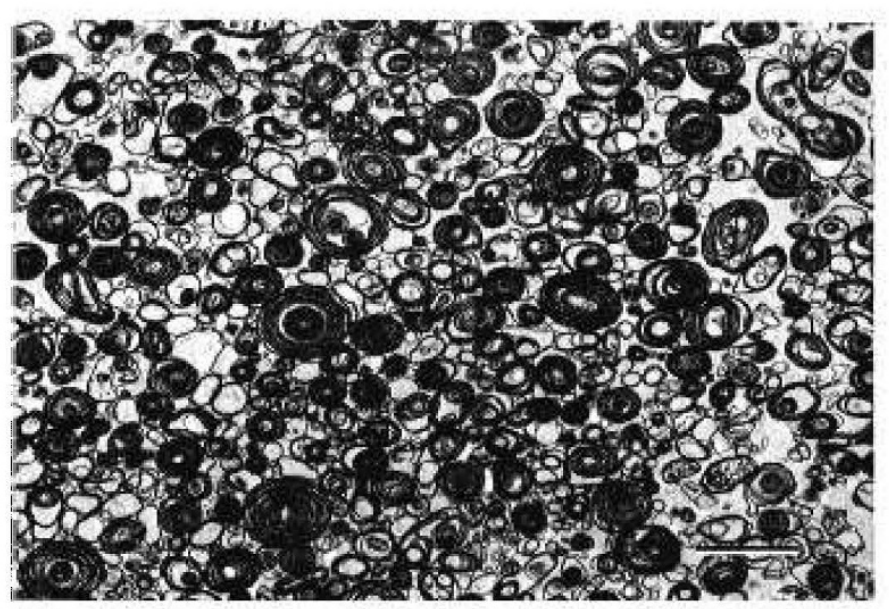

Fig. 1. Low power electron micrograph of pelleted lamellar body fraction from a newborn rat, isolated according to Duck-Chong (8). The fraction was floated to the $0.4 \mathrm{M}$ sucrose level, aspirated, and diluted to $0.2 \mathrm{M}$ sucrose containing $2 \%$ bovine serum albumin plus $3 \mathrm{mM}$ EDTA and pelleted at $100,000 \times g$ for $1 \mathrm{~h}$. Fixation was in $2 \%$ glutaraldehyde plus $2 \%$ tannic acid and $1 \% \mathrm{OsO}_{4}$. Bar equals $2 \mu \mathrm{m}$.

Table 1. Unlavaged lung [mean $\pm \operatorname{SEM}(n)]$

\begin{tabular}{|c|c|c|c|c|}
\hline & Birth* & $+10 \mathrm{Min} t$ & $+2 \mathrm{H}$ & $+24 \mathrm{H}$ \\
\hline Body wt (g) & $\begin{array}{c}6.99 \pm 0.14 \\
(13)\end{array}$ & $\begin{array}{c}7.09 \pm 0.19 \\
(14)\end{array}$ & $\begin{array}{c}7.72 \pm 0.08 \ddagger \\
(26)\end{array}$ & $\begin{array}{c}8.36 \pm 0.16 \neq \\
(22)\end{array}$ \\
\hline Lung wet wt (g) & $\begin{array}{c}0.172 \pm 0.006 \\
\text { (13) }\end{array}$ & $\begin{array}{c}0.155 \pm 0.007 \ddagger \\
(14)\end{array}$ & $\begin{array}{c}0.131 \pm 0.004 \$ \\
(14)\end{array}$ & $\begin{array}{c}0.137 \pm 0.003 \ddagger \\
(14)\end{array}$ \\
\hline Dry/wet ratio & $\begin{array}{c}0.143 \pm 0.004 \\
(10)\end{array}$ & $\begin{array}{c}0.146 \pm 0.003 \\
(8)\end{array}$ & $\begin{array}{c}0.188 \pm 0.002 \ddagger \\
(8)\end{array}$ & $\begin{array}{c}0.184 \pm 0.002 \ddagger \\
(10)\end{array}$ \\
\hline LB DSPC (mg/g dry lung) & $\begin{array}{c}5.33 \pm 0.91 \\
(5)\end{array}$ & $\begin{array}{c}6.71 \pm 0.95 \ddagger \\
(5)\end{array}$ & $\begin{array}{c}6.23 \pm 0.46 \\
(6)\end{array}$ & $\begin{array}{c}7.22 \pm 0.12 \ddagger \\
(6)\end{array}$ \\
\hline
\end{tabular}

\footnotetext{
* Immediately prior to air breathing.

$\uparrow 10 \mathrm{~min}$ of air breathing.

$\$$ Different from birth, $p<0.05$.
} 
another group of newborns after performing extensive lung lavage (Table 3 ). The recovery of fluid from the nine lavages in each lung exceeded $75 \%$ of the total instilled fluid. At the time of birth, but before air breathing began, the lavage DSPC pool was small (Table 3). After $10 \mathrm{~min}$ of air breathing the lavage lipid pool is larger, but there was no net change in the lamellar body pool. At $24 \mathrm{~h}$ of age, lavaged lungs showed a smaller lamellar body pool and a continuing rise in DSPC recovered in the lavage. The net increase in whole lung DSPC was accounted for by the rise in lavage fluid DSPC. LDH in lavage fluid always averaged less than $0.5 \%$ of tissue LDH (Table 3 ).

Subfractions of the lavage fluid were collected from pooled lavages of approximately five fetal or newborn or one adult animal for each single determination (Table 4). Figure 2 shows the measured total PL in pellet $3(1000 \times g \times 20 \mathrm{~min})$ and the sum of pellet 5 (P5) and the final supernatant (S5) obtained at $100,000 \times g \times 16 \mathrm{~h}$. Modest changes occurred in all fractions, except for the larger ones observed in S5. Ratios between P3 and P5 plus S5 drop sharply from 3 at birth to approximately adult values $(0.15)$ by $24 \mathrm{~h}$ of age. Electron micrographs from pellet 3 and pellet 5 are shown in Figure 3. There were numerous tubular myelin figures present in pellet 3 , while pellet 5 uniformly consisted of unilamellar figures, as previously reported by Magoon et al. (10) for adult rabbits.

Table 2. Morphometric estimates of type II cell organelle volume densities $\left(V_{\mathrm{I}}\right)$ in unlavaged rat lungs (mean $\left.\pm S E M\right)$

\begin{tabular}{lccc}
\hline & Birth & $+10 \mathrm{Min}$ & $+24 \mathrm{H}$ \\
\hline Organelle $\mathrm{V}_{\mathrm{v}}(\%)$ & $n=6$ & $n=5$ & $n=3$ \\
Cytoplasm & $53 \pm 1.6$ & $52 \pm 0.5$ & $46 \pm 1.3$ \\
Nucleus & $37 \pm 1.1$ & $37 \pm 0.8$ & $41 \pm 2.3$ \\
Mitochondria & $5.4 \pm 0.7$ & $5.0 \pm 0.3$ & $6.4 \pm 0.7$ \\
Lamellar body & $4.5 \pm 0.2$ & $6.2 \pm 0.4^{*}$ & $6.2 \pm 1.6$ \\
\hline
\end{tabular}

$* p<0.05$, compared to birth (immediately prior to air breathing) value.

Table 3. Lavaged lung DSPC (mean \pm SEM)

\begin{tabular}{lccc}
\hline & $\begin{array}{c}\text { Birth* } \\
(n=4)\end{array}$ & $\begin{array}{c}+10 \text { Min } \\
(n=5)\end{array}$ & $\begin{array}{c}24 \mathrm{H} \\
(n=12)\end{array}$ \\
\hline $\begin{array}{c}\text { Lavage DSPC (mg/g } \\
\text { dry lung) }\end{array}$ & $1.78 \pm 0.92$ & $4.77 \pm 0.86 \ddagger$ & $11.08 \pm 0.57 \ddagger$ \\
$\begin{array}{c}\text { LB DSPC (mg/g dry } \\
\text { lung) }\end{array}$ & $5.21 \pm 0.62$ & $4.85 \pm 0.94$ & $4.28 \pm 0.34 \ddagger$ \\
$\begin{array}{c}\text { Whole Lung DSPC } \\
\text { (mg/g dry lung) }\end{array}$ & $24.13 \pm 1.05$ & $21.92 \pm 0.94$ & $32.77 \pm 1.5 \ddagger$ \\
$\begin{array}{c}\text { Lavage LDH (\% tis- } \\
\text { sue LDH) }\end{array}$ & $0.41 \pm 0.07$ & $0.10 \pm 0.06 \ddagger$ & $0.10 \pm 0.02 \ddagger$ \\
\hline
\end{tabular}

\section{* Immediately prior to air breathing.}

$\dagger 10 \mathrm{~min}$ of air breathing. Whole lung DSPC includes tissue and lavage pools.

$\ddagger$ Different from birth, $p<0.05$.

\section{DISCUSSION}

The redistribution after birth of intracellular and extracellular surfactant pools has been frequently measured $(3,4,6,7,12,18$, 19) although many studies used data obtained several hours to days after birth. The report of Fariday et al. (7) contains measures from fetuses and very young newborns. The focus of our study was to obtain both biochemical and morphometric data within

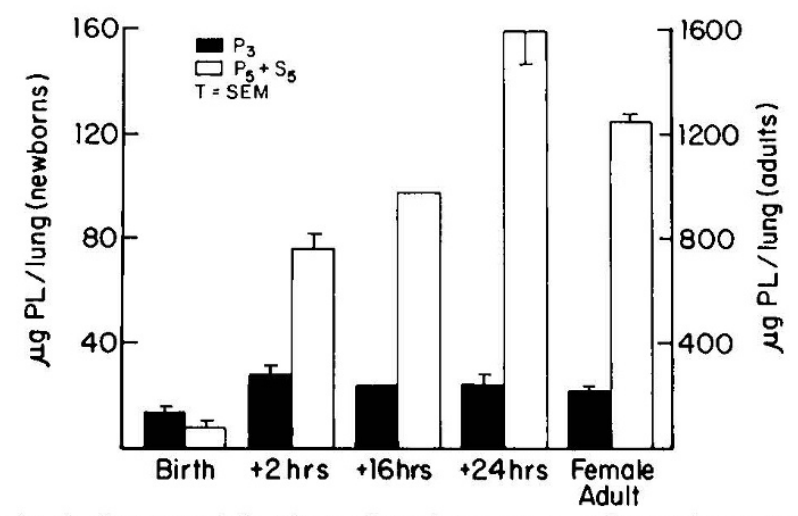

Fig. 2. Lavage subfractions of newborn rat pups immediately before air breathing $(B I R T H)$ and after 2 to $24 \mathrm{~h}$ of air breathing. $P 3=$ pellet collected after $1000 \times g$ for $20 \mathrm{~min} . P 5=$ pellet collected after 1000,000 $\times g \times 16$ h. S5 $=$ supernate remaining after all centrifugation steps. The greatest increase in PL from newborn lavage fluid is in the combined P5 $+\mathrm{S} 5$ fractions. Adult lavage values are given according to the right ordinate.

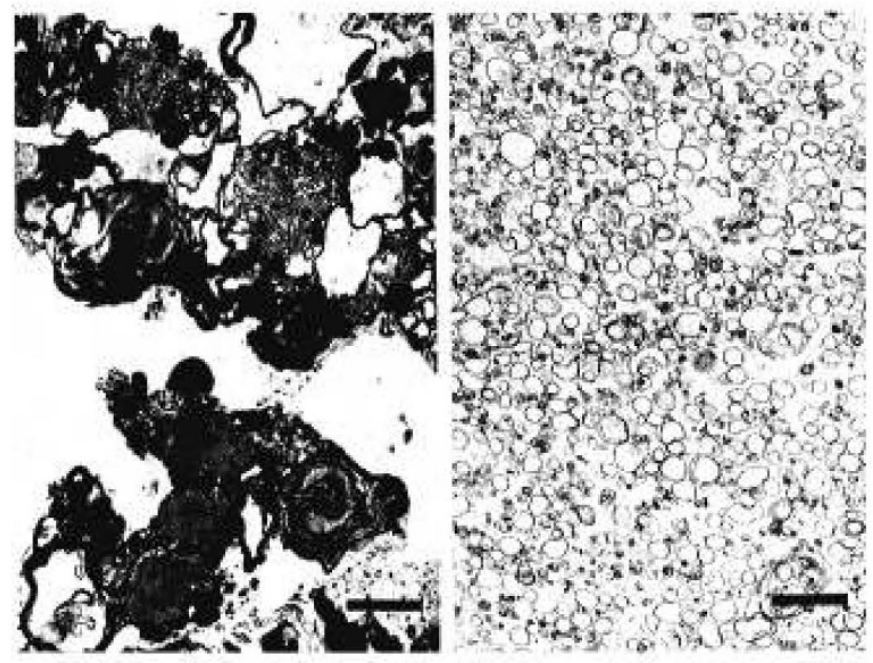

Fig. 3. Electron micrographs of pelleted lavage subfraction $\mathrm{P} 3$ (left) and P5 (right). Both at same magnification (original $\times 11,500$, bar equals $1 \mu \mathrm{m})$. The P3 material was $9 \%$ tubular myelin by point counting volumetry. P5 was uniformly composed of unilamellar vesicular material.

Table 4. Distribution of PL among lavage subfractions ( $\mu$ g PL/lung) (mean $\pm S E M$ )

\begin{tabular}{lccccc}
\hline $\begin{array}{c}\text { Subfraction* } \\
\text { ( } g \text { force) }\end{array}$ & $\begin{array}{c}\text { Birth } \dagger \\
(n=8)\end{array}$ & $\begin{array}{c}+2 \mathrm{H} \\
(n=4)\end{array}$ & $\begin{array}{c}16 \mathrm{H} \\
(n=2)\end{array}$ & $\begin{array}{c}24 \mathrm{H} \\
(n=4)\end{array}$ & $\begin{array}{c}\text { Adult female } \\
(n=6)\end{array}$ \\
\hline P1 $(50)$ & ND & $44 \pm 11$ & ND & $55 \pm 4$ & ND \\
P2 $(500)$ & $23 \pm 5$ & $60 \pm 18$ & 60 & $77 \pm 13$ & $385 \pm 29$ \\
P3 (1000) & $13 \pm 1$ & $28 \pm 3$ & 24 & $24 \pm 4$ & $213 \pm 34$ \\
P4 (60000) & $22 \pm 4$ & $45 \pm 7$ & 28 & $37 \pm 4$ & $478 \pm 45$ \\
P5 (100000) & $6 \pm 2$ & $14 \pm 1$ & 31 & $55 \pm 13$ & $599 \pm 110$ \\
S5 & $1.3 \pm 0.2$ & $63 \pm 6$ & 67 & $107 \pm 20$ & $660 \pm 127$ \\
\hline
\end{tabular}

* P1 through P5 represent the pelleted material obtained by centrifuging the lavage fluid at the $\mathrm{g}$ forces indicated. Our protocol was taken from Magoon et al. (10). S5 represents the total supernate remaining over pellet P5.

$\uparrow$ Immediately prior to air breathing.

$\$$ Not determined. 
a short time after birth. We expected a rapid shift of intracellular surfactant (lamellar body volume) into the alveolar space to occur. Further, we wished to measure changes occurring in the distribution of lavage-derived surfactant subfractions, separated by the scheme of Magoon et al. (10), in order to test predictions of metabolic relationships between extracellular physical forms.

When compared to fetal values, lamellar body DSPC rose $26 \%$ at +10 min and was $35 \%$ greater at $24 \mathrm{~h}$ of age. These results were from unlavaged lungs (Table 1). The morphometric results of Table 2 agree with the biochemical estimates of lamellar body pool size and indicate a small rise in the lamellar body pool after birth in unlavaged lungs. It is possible that the lamellar body isolation procedures result in contamination of the isolates with extracellular DSPC (8). If true, this would result in an overestimate of the lamellar body pool. The lamellar body DSPC pool estimated from lavaged lungs (Table 3 ) was also unchanged after $10 \mathrm{~min}$ of air breathing, despite the larger recovery of DSPC in the lavage fluid at $10 \mathrm{~min}$. By using unpublished data from our laboratory (Young SL, unpublished data), we calculated the total morphometric lamellar body pool to be $0.018 \pm 0.002$ $\mathrm{mm}^{3} / \mathrm{mg}$ dry lung $(n=6)$ at birth and $0.021 \pm 0.004 \mathrm{~mm}^{3} / \mathrm{mg}$ dry lung $(n=5)$ after 10 min of air breathing. For these reasons, we believe that rat intracellular surfactant pools are not depleted after birth, at least at the time periods we studied.

The amount of DSPC recovered by alveolar lavage did increase substantially after birth (Table 3 ). We obtained 2.7 times more lavage DSPC at $10 \mathrm{~min}$ and 6.8 times more at $24 \mathrm{~h}$ compared to that present at birth. This pattern of a rapid accumulation of phospholipid in the lavage was expected from several previous reports $(3,4,6,19)$.

The lavage procedure may stimulate the release of lamellar body DSPC (20) even though we used iced solutions. The difference between the lamellar body pools in unlavaged (Table 1) and lavaged (Table 3) lungs may represent lamellar body DSPC release stimulated by our lavage procedure.

We examined the redistribution of the newly secreted lavage phospholipids by employing the subfractionation scheme of Magoon et al. (10). In their work with adult rabbits, they showed that P1 and P2 were rich in cellular material, P3 was enriched in tubular myelin, and P5 and S5 contained large amounts of unilamellar vesicles. Wright et al. (21) also showed P3 adsorbed to the air-liquid interface rapidly and contained large amounts of a lung-specific apoprotein, while P5 and S5 did not adsorb nearly as rapidly and had a much lower content of the same apoprotein. Finally, this group demonstrated a precursor-product relationship between P3 and P5 (10,21). Our finding in neonatal rat lung lavage subfractionated by similar techniques are shown in Table 4.

At birth, fetal lungs contain twice as much PL in P3 as in the P5 plus S5 fractions. During the first $2 \mathrm{~h}$ of air breathing, this changed with a doubling of P3 but an increase in P5 plus S5 of 10-fold. By 24 h, P3 was unchanged and P5 plus S5 doubled again. The ratio of P3 to P5 plus S5 was 0.15 at $24 \mathrm{~h}, 20$ times less than at birth. This distribution at $24 \mathrm{~h}$ is similar to that of the adult female rat lungs (mothers of the neonates). If the functional and metabolic relationships in fetal rat lungs and adult rabbit lavage subfractions are the same, the results of Table 4 suggest a relative stability of the lavage tubular myelin-rich fraction and a substantial increase in a presumed degradation product, P5 plus S5. Our finding that P3 and P5 are structurally the same in the neonatal rat lung (Fig. 3) and the adult rabbit lung lavage is compatible with the analysis of Magoon et al. (10). A precursor-product relationship demonstrated by radiolabeled studies would help support these notions, but is difficult to perform in fetal rats.

Our lavage subfraction results could be interpreted as supporting the hypothesis that P3 reflects newly secreted material and P5 plus S5 represent degradation of PL forms having been cycled through the air-liquid interface. Thus at birth, but before air breathing, much of the small extracellular PL pool might be in the form of material that is a precursor to the adsorbed monolayer and contains tubular myelin. As the extracellular PL accumulates with the onset of air breathing, it may be converted to a form sedimenting only at higher centrifugal forces and which consists mainly of unilamellar vesicles. Within $24 \mathrm{~h}$, adult ratios of the surfactant subfractions are present. Baritussio et al. (18) have presented similar results in newborn rabbits.

Because the purity and yield of the surfactant subfractions are uncertain, the quantitative relationship between the different extracellular physical forms of surfactant PL cannot be accurately calculated from our results. Nevertheless, we propose that it is likely that a minority of the lavage PL is available for rapid adsorption to the air-liquid interface within hours after birth. Thus, studies of the sufficiency of the alveolar surfactant pool should consider the distribution of lavage PL into subfractions, which could affect interpretations of such experiments. Clinically important decisions, such as prediction of the need for surfactant therapy, might be significantly affected.

We conclude that large increases in alveolar space DSPC occur within $10 \mathrm{~min}$ of air breathing. Surfactant DSPC pools increase substantially throughout the first $24 \mathrm{~h}$ of life. There is no depletion of the rat lung lamellar body pool at early times in postnatal life when lavage DSPC is increasing most rapidly. Since the source of alveolar space DSPC is most likely type II cells, and since there is no depletion of the intracellular DSPC pools, these cells must either be capable of rapid de novo synthesis or be able to be supplied with lamellar body DSPC from unexpected sources from within this cell type, from other lung cells or from extracellular sources. Changes in the distribution of PL between subfractions of lavage fluid are consistent with prior hypotheses of the sequential physical changes occurring after secretion of surfactant $(10,15,21,22)$. These observations may be used to advantage in the study of surfactant metabolism disease states and their treatment.

Aknowledgments. The authors are grateful to Drs. Robert Mercer and Scott Randell for helpful discussions, to Erick Larson and Dennis Wen for technical assistance, and to Mary Elks for typing the manuscript.

\section{REFERENCES}

1. Rooney SA, Gobran LI, Wai-Lee TS 1977 Stimulation of surfactant production by oxytocin-induced labor in the rabbit. J Clin Invest 60:754-759

2. Jacobs H, Jobe A, Ikegami M, Jones S 1982 Surfactant phosphatidylcholine source, fluxes, and turnover time in 3-day-old, 10-day-old, and adult rabbits. J Biol Chemical 257:1805-1810

3. Jobe A, Ikegami M, Jacobs H 1981 Changes in the amount of lung and airway phosphatidylcholine in 0.5-12.5 day-old rabbits. Biochim Biophys Acta 664:182-187

4. Clements JA, Tooley WH 1977 Kinetics of surface-active material in the fetal lung. In: Hodson WA (ed) Development of the Lung. Decker, New York, pp 349--366

5. Krasno JR, Knelson JH, Dalldorf FG 1972 Changes in the alveolar lining with onset of breathing. Am J Pathol 66:271-476

6. Lawson EE, Birdwell RL, Huang DS, Taeusch HW Jr 1978 Augmentation of pulmonary surfactant secretion by lung expansion at birth. Pediatr Res 13:611-614

7. Fariday EE, Thliveris JA, Morris GS 1981 Relationship between lung intra and extracellular DSPC in fetal and neonatal rats. Respir Physiol 45:55-56

8. Duck-Chong CG 1978 The isolation of lamellar bodies and their membranous content from rat lung, tracheal fluid and human amniotic fluid. Life Sci 22:2025-2030

9. Thet LA, Clerch L, Massaro GD, Massaro D 1979 changes in sedimentation of surfactant in ventilated excised rat lungs. J Clin Invest 64:600-603

10. Magoon MW, Wright JR, Baritussio A, Williams MC, Goerke J, Benson BJ, Hamilton RL, Clements JA 1983 Subfractionation of lung surfactant. Implications for metabolism and surface activity. Biochim Biophys Acta 750:18-31

11. Bligh ER, Dyer WJ 1959 A rapid method of total lipid extraction and purification: Can J Biochem 37:911-917

12. Folch J, Lees M, Sloane-Stanley GH 1957 A simple method for the isolation and purification of total lipids from animal tissue. J Biol Chem 226:457505

13. Mason RJ, Nellenbogen J, Clements JA 1976 Isolation of disaturated phosphatidylcholine with osmium tetroxide. J Lipid Res 17:281-284

14. Bartlett GR 1959 Phosphorus assay in column chromatography. J Biol Chem $234: 466-468$ 
15. Williams MC 1977 Conversion of lamellar body membranes into tubular myelin in alveoli of fetal rat lungs. J Cell Biol 72:260-277

16. Young SL, Kremers SA. Apple JS. Crapo JD. Brumley GW 1981 Rat lung surfactant kinetics: biochemical and morphometric correlations. $J$ Appl Physiol 51:248-253

17. Dunnett CW $1955 \mathrm{~A}$ multiple comparison procedure for comparing several treatments with a control J Am Stat Assoc 50:1096-1121

18. Baritussio A. Bruni R. Benevento M. Gabelli C 1986 Alveolar pools of saturated lecithin and isoforms of surfactant-associated proteins change during the first day of life in the rabbit. Fed Proc 45:908(abstr)
19. Marino PA, Rooney SA 1981 The effect of labor on surfactant secretion in newborn rabbit lung slices. Biochem Biophys Acta 664:389-396

20. Fariday EE 1976 Effect of distension on release of surfactant in excised dogs' lungs. Respir Physiol 27:99-114

21. Wright JR, Benson BJ, Williams MC, Goerke J, Clements JA 1984 Protein composition of rabbit alveolar surfactant subfractions. Biochim Biophys Acta 791:320-332

22. Baritussio A, Carraro R, Bellina L, Rossi A, Bruni R, Pettenazzo A, Enzi G 1985 Turnover of phospholipids isolated from fractions of lung lavage fluid. J Appl Physiol 59:1055-1060

\section{Annual Meeting}

The Annual Meeting of the European Society for Pediatric Research will be held in Padova, Italy, September 6-10, 1987. The main topics are Immunology, Nutrition, Pediatric Epidemiology, Neonatology, Oncology, Neurology. Deadline for submitting abstracts is April 15, 1987. A few travel bursaries will be available for young investigators of Eastern countries.

For further information contact: Prof. F. F. Rubaltelli, Dept. di Pediatria, Via Giustiniani, 3, 35128 Padova, Italy. 